\title{
Formulation and Optimization of Furosemide Snedds With Variation Concentration of Tween 80 and PEG 400
}

Sesilia Putri Nandita; Ilham Kuncahyo; Reslely Harjanti*

Departement of Pharmacy, Faculty of Pharmacy, Universitas Setia Budi, Jl. Letjen Sutoyo, Mojosongo, Kec. Jebres, Kota Surakarta, Jawa Tengah 57127.

\section{Abstract}

Furosemide is a potent diuretic drug that has low bioavailability. Furosemide can be formulated into nanoemulsion preparations using the SNEDDS method to increase its bioavailability as SNEDDS can form stable nanoemulsions with droplet sizes $<200 \mathrm{~nm}$. This study aims to identify the optimum formula for variations in the concentration of surfactant Tween 80 and cosurfactant PEG 400 based on the characterization tests of emulsification time, percent transmittance, and drug loading. The independent variables used in this study were Tween 80 and PEG 400. Seven furosemide SNEDDS formulas from the Simplex Lattice Design (SLD) method were tested for characterization in the form of emulsification time, percent transmittance, and drug loading. The characterization results were optimized using Simplex Lattice Design. The optimum formula was re-characterized, including emulsification time, percent transmittance, drug loading, particle size, zeta potential, and in vitro dissolution. The results were then compared with theoretical values and analyzed using the One-Sample T-test method. Optimization results showed Tween of $61.4922 \%$ and PEG 400 of $18.5078 \%$ with the characterization of emulsification time 15.25 seconds, percentage transmittance $94.20 \%$, drug loading 50 $100.2 \mathrm{ppm}$, particle size $12.18 \mathrm{~nm}$. Furthermore, the zeta potential was $-17.6 \mathrm{mV}$, and the in vitro dissolution rate reached $106.71 \%$ within 15 minutes.

\section{Data of article}

Received : 01 July 2021

Reviewed : 20 July 2021

Accepted : 24 Aug 2021

DOI

10.18196/jfaps.v2i1.12180

Type of article:

Research

Keywords: furosemide; SNEDDS; tween 80; PEG 400; SLD

\section{INTRODUCTION}

Furosemide is commonly used as a potent diuretic in treating edema associated with heart, renal, hepatic, and hypertension failure. ${ }^{1}$ Furosemide belongs to the Biopharmaceutical Class System (BCS) of class IV with low permeability and solubility. Low solubility and permeability are important factors responsible for the low bioavailability of furosemide. The bioavailability of oral furosemide varies from $50-61 \%$; thus, efforts are needed to overcome this problem. ${ }^{2}$ The low solubility of furosemide can be solved by using a lipid-based formulation with a nanosystem such as the self-Nano emulsifying drug delivery system (SNEDDS). ${ }^{3}$ SNEDDS is an isotropic mixture system of the oil phase,

\footnotetext{
*Corresponding author, e-mail: lely.harjanti@gmail.com
} 
surfactant, and co-surfactant. When SNEDDS is absorbed into the body, the preparation will quickly disperse to form droplets $<200 \mathrm{~nm}$ in size and will form O/W (oil in water) nanoemulsions spontaneously in the gastrointestinal tract $^{4}$.

The components used in this study were oleic acid oil, surfactant Tween 80, and cosurfactant PEG 400. The oil component in the SNEDDS formulation acts as a drug carrier or active substance. In contrast, the surfactant and cosurfactant components reduce droplet size, emulsion and retain the active substance at the absorption site without deposition in the gastrointestinal tract. 5

A good SNEDDS formula was determined from various parameters, including percent transmittance, particle size, drug loading, zeta potential, emulsification time, and in vitro dissolution. The steps before determining the optimum formula were carried out using the Simplex Lattice Design (SLD). The advantage of using this application is to increase the effectiveness in interpreting factors and interactions. The desired effect with no interaction can be predicted to make the study more efficient. ${ }^{6}$ Based on the background above, this study aims to obtain the optimum formula using various concentrations of surfactant Tween 80 and cosurfactant PEG 400 according to the characterization test of emulsification time, percent transmittance, and drug loading.

\section{METHOD}

This study is experimental laboratory research to identify the optimization of the formula of SNEDDS furosemide with various concentrations of Tween 80 and PEG 400 using the simplex lattice design method. This study was conducted at the Research Laboratory of the Faculty of Pharmacy, Setia Budi University, for two months.

\section{Research Tools and Materials \\ This research utilized UV spectrophotometer (UV-180o Series), centrifuge (Table Top Centrifuge PLC-05 1601461), dissolution with basket stirrer type (Erweka type DT 700), analytical balance (Ohaus PA213 $1 \mathrm{mg}$ accuracy and Ohaus AV26422 $0.1 \mathrm{mg}$ accuracy), magnetic stirrer, and laboratory glassware.}

Meanwhile, the materials used in this study were pure furosemide obtained from PT. Graha Farma, Oleic Acid, Tween 80, and PEG 400 obtained from PT. Brataco Chemika Solo, aquadestilata, and methanol p.a obtained from the pharmaceutical Technology Laboratory of Universitas Setia Budi.

\section{Determination of SNEDDS formulation}

Preparation of the furosemide SNEDDS formula used the simplex lattice design (SLD), specifically Design Expert 10.0.3. The use of the SLD method was based on two independent variables whose application was used to determine the optimal formula for the mixture of ingredients. The SLD design in the study was made by choosing three combinations and observing the response obtained.7

\section{Preparation of furosemide SNEDDS}

Formulation of SNEDDS furosemide of 3 $\mathrm{mL}$ was put into the vial by taking each ingredient according to run (7 runs). It was then stirred using a magnetic stirrer at a speed of $50 \mathrm{rpm}$. After forming an isotropic mixture, furosemide was added gradually until a cloudy solution was obtained. The stirring process was continued for 24 hours, and centrifugation 
was carried out to separate the insoluble part of the furosemide at a speed of 5000 rpm. The clear supernatant was taken and then characterized, which included emulsification time, percent transmittance, drug loading, particle size, zeta potential, and in vitro dissolution test. $^{8}$

\section{Furosemide SNEDDS Optimization}

The results of the SNEDDS formula were entered in the Simplex Lattice Design (SLD) program so that one optimum formula was obtained for SNEEDS furosemide. The optimum formula was expected to achieve the set parameters consisting of emulsification time $<3$ minutes, particle size $<200 \mathrm{~nm}$, zeta potential $\pm 30 \mathrm{mV}$, percent transmittance approaching 100\%, high drug loading, and dissolution of less than $80 \% .^{8}$

\section{Characterization of the optimum formula of furosemide SNEDDS}

Emulsification time. 100.0 L of furosemide SNEDDS was mixed into $10 \mathrm{ml}$ of distilled water, then mixed using a magnetic stirrer at a speed of $50 \mathrm{rpm}$ while observing the time for emulsification using a stopwatch. ${ }^{8}$

Transmittance percent. The SNEDDS formula resulting from the emulsification time was based on transmittance using UV-Vis spectrophotometry at a 200-650 $\mathrm{nm}$ wavelength and aquadestilata blank. ${ }^{8}$

Drug loading. The sample of furosemide SNEDDS was pipetted $0.1 \mathrm{~mL}$, and it was put into a $10 \mathrm{~mL}$ volumetric flask; then, the volume was added with methanol p.a to the limit mark and shaken.

Particle size and zeta potential. The SNEDDS formulation has been taken 10 $\mathrm{mL}$ using a volume pipette then put into a $100.0 \mathrm{~mL}$ volumetric flask. The volume was adjusted to the mark with distilled water, homogenized using a magnetic stirrer, and then measured using a Zetasizer. $^{8}$

In vitro dissolution. The dissolution profile of SNEDDS furosemide was compared with pure furosemide powder filled into soft shells. The dissolution test was carried out using a dissolution apparatus type 1 (Basketball) with $900 \mathrm{~mL}$ of $0.1 \mathrm{~N} \mathrm{HCl}$ media. The temperature was set at $37 \pm 0.5^{\circ} \mathrm{C}$, and the rotation speed was $50 \mathrm{rpm}$. At minute 0 , the capsule was put into the medium. At minutes of 5,10 , $15,20,25,30,35$, and $60,5 \mathrm{ml}$ of the solution was taken and re-replaced with an equivalent volume of the same type of dissolution medium at the same temperature. ${ }^{9}$

\section{Data analysis}

The optimum formulation of furosemide SNEDDS obtained from the design expert was tested for characteristics including emulsification time, percent transmittance, and drug loading and then tested for normality.) with a $95 \%$ confidence level. The test was carried out by comparing the results obtained from the normality test with the theoretical requirements. It would meet the requirement if the sig value was $>0.05$.

\section{RESULTS AND DISCUSSION}

The furosemide SNEDDS formula was obtained using the Simplex Lattice Design (SLD) by stating the upper and lower limits of the ingredients used in Tween 80 with a range of $60 \%-65 \%$ and PEG 400 with a range of $15 \%-20 \%$. In comparison, it was set at $20 \%$ for oleic acid to obtain some suggested formulations. The furosemide drug delivery system from 7 formulas obtained using expert design was 
characterized by the emulsification time, percent transmittance, and drug loading.

The best emulsification time and percent transmittance were obtained by formula 7. The emulsification time was carried out to obtain an idea of the time required for furosemide SNEDDS to form a precise proportion of nanoemulsion when interacting with the gastrointestinal tract in the body. The transmittance percentage was used to determine the furosemide SNEDDS included in the nanoemulsion with clarity of consistency close to $100 \%$. The highest drug loading produced by formula 3 was 58583.3 ppm since the most significant surfactant component was found in formula 3. Surfactants were able to help the oil component dissolve the drug so that a high drug loading was obtained.

Table 1. Furosemide SNEDDS formulation and characterization

\begin{tabular}{ccccc}
\hline $\begin{array}{c}\text { Tween 8o } \\
(\%)\end{array}$ & $\begin{array}{c}\text { PEG 400 } \\
(\%)\end{array}$ & $\begin{array}{c}\text { Emulsification time } \\
\text { (seconds) }\end{array}$ & $\begin{array}{c}\text { Percent } \\
\text { transmittance } \\
(\%)\end{array}$ & $\begin{array}{c}\text { Drug loading } \\
\text { (ppm) }\end{array}$ \\
\hline 60 & 20 & $26 \pm 0.667$ & $98.2 \pm 0.2$ & 33670.6 \\
63.75 & 16.25 & $43 \pm 0.12$ & $82 \pm 11.99$ & 49481.2 \\
65 & 15 & $107 \pm 0.667$ & $93 \pm 1.2$ & 58583.3 \\
62.5 & 17.5 & $23 \pm 0.333$ & $81 \pm 11.86$ & 44882.9 \\
61.6667 & 18.3333 & $26 \pm 0.333$ & $92.53 \pm 2,72$ & 40001.2 \\
63.3333 & 16.6667 & $29 \pm 0.12$ & $79.2 \pm 6,17$ & 43056.2 \\
61.25 & 18.75 & $13 \pm 0.667$ & $98.27 \pm 1.13$ & 41575.9 \\
\hline
\end{tabular}

Contour plots of emulsification time and percent transmittance showed how the combination of surfactant and cosurfactant components influenced each other, as seen in the curved graph. Meanwhile, the two did not affect each other for drug loading. The regression coefficient value obtained from the design expert showed that the interaction of the surfactant and cosurfactant components had an effect on decreasing the emulsification time; the surfactant component led to an increase in the transmittance percentage value while the cosurfactant component led to an increase in drug loading.
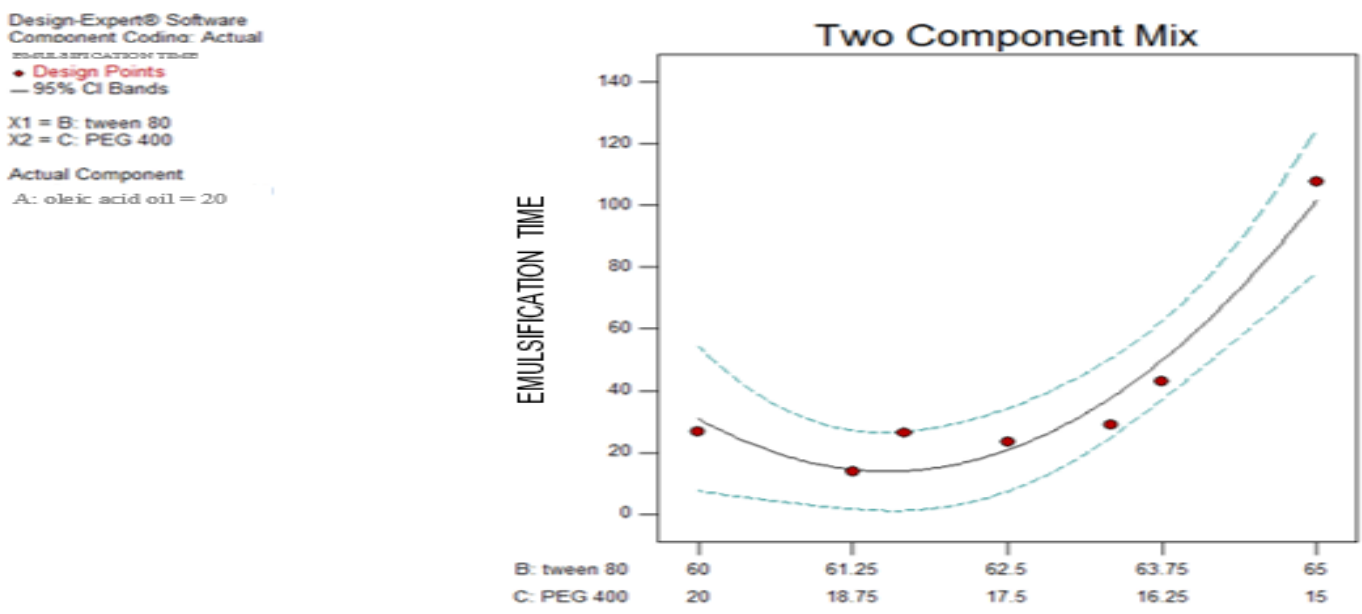

Figure1. Contour plot of emulsification time 

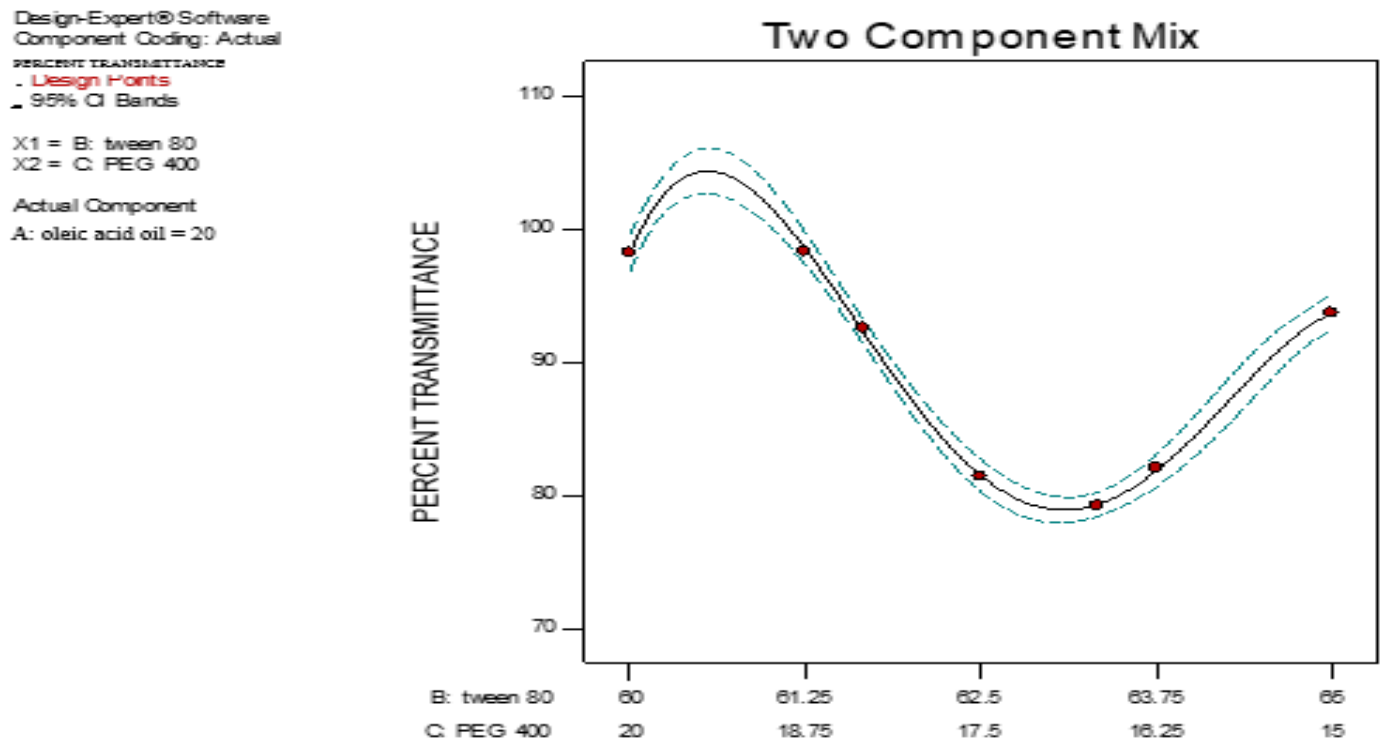

Figure 2. Contour plot of percent transmittance

Dosign-Exporttos Software

Componant Coding: Actui

Derign Points

- Design Poirts
$-95 \%$ CI Bands

X1 = B: tweon 80

$X 2=C: P E G 400$

Actual Component

A: oleic acid oil $=20$

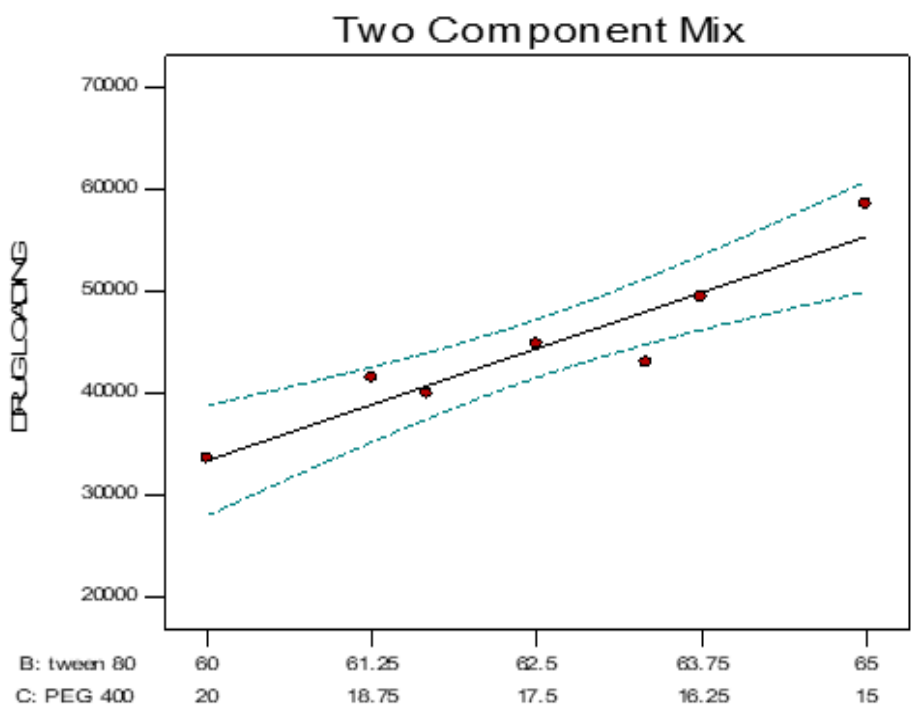

Figure 3. Contour plot of drug loading

The optimum formula of furosemide SNEDDS was determined based on the emulsification time, drug loading, and percent transmittance of characterization test results. Based on the seven formulas, an optimization study was conducted using Simplex Lattice Design in the Design Expert 10 program.

The results obtained on the characterization of the emulsification time of the optimum formula of furosemide
SNEDDS did not significantly differ from the experiments carried out using the Simplex Lattice Design. The emulsification time obtained from the

optimum formula was included in the class 2 category, where the emulsification time formed was quite fast by producing a transparent emulsion system. It occurred since the more surfactant and cosurfactant compositions could accelerate the formation of emulsions 
when in contact with the medium (aquadestylates).

The transmittance percentage close to $100 \%$ indicated that the optimum formula produced a clear and transparent dispersion with a droplet size estimated to reach nanometers. When light passed through an emulsion system with tiny droplet sizes, the light beam would be transmitted so that the color of the solution looked transparent and the resulting transmittance was more excellent. ${ }^{10}$

Meanwhile, drug loading was used to determine the ability of SNEDDS in dissolving the drug until it was adequately saturated and determining the drug content in the SNEDDS formula. ${ }^{11}$ The results of drug loading between predictions from Simplex Lattice Design and the experiment were not highly different. The drug loading value obtained was relatively large. It was used to determine how much volume of SNEDDS was needed for one use by comparing the usual dose of a one-time use of furosemide with the drug loading level.

The results of the particle size characterization above showed that the optimum formula for SNEDDS had entered the nano range. Particle size analysis was an essential factor in evaluating a nanoemulsion formula. Particle size was known to affect drug absorption, as studied by various researchers. The stability of nanoemulsions also depends on the size of the particles. The smaller the size of the particles is formed, the better the stability of the emulsion will be ${ }^{12}$ The most influential component in SNEDDS in the formation of nanoparticles was the surfactant component (Tween 80). High concentrations of surfactants would increase water penetration into the oil droplets, leading to its breakdown. ${ }^{13}$

Furthermore, eta potential can be used to estimate the surface characteristics of nanoemulsions. The zeta potential value greater or farther from o will cause the preparation to be more stable due to the formation of an electric double layer, which prevents the incorporation of particles in the formula ${ }^{14}$. In the case of this study, the result obtained above showed that the potential zeta value of the optimum formula was adequate, indicating a stable system.

The furosemide SNEDDS dissolution test result was portrayed by a graph between the time and \% dissolution of the drug dissolving in $0.1 \mathrm{~N} \mathrm{HCl}$ medium, which described the in vitro drug release profile. This parameter was called the dissolution efficiency parameter ${ }^{15}$. The dissolution test results showed that the furosemide SNEDDS formula already had a high concentration starting from the $5^{\text {th }}$ minute of dissolution, $86.08 \%$. Moreover, the highest concentration was obtained at the $15^{\text {th }}$ minute with a concentration of $106.71 \%$. The high levels in the early minutes of dissolution were due to the SNEDDS formulation, which could form spontaneous nano-emulsions when in direct contact with water or gastrointestinal fluids in the digestive tract. Therefore, the body would quickly absorb the drug.

Verification of the optimum formula was carried out to determine whether there was a significant difference between the characterization of the experimental results and the characterization of the predictions of Simplex Lattice Design. Statistical analysis using a one-sample ttest showed that the emulsification time of characterization test, drug loading 
determination, and percent transmittance in the experiment was compared with predictions using Simplex Lattice Design (predicted results). The results were not significantly different, with a $\mathrm{p}$-value > 0.05 , indicating that the optimum formula was valid and verified.

Table 2. The characterization of furosemide SNEDDS optimum formula

\begin{tabular}{lll}
\hline Parameters & SLD prediction result & Experiment result \\
\hline Emulsification time (seconds) & 13.9 & $15.25 \pm 0.99$ \\
Percent transmittance (\%) & 95.32 & $94.20 \pm 1.51$ \\
& & \\
Drug loading (ppm) & 52603.4 & $50100.2 \pm 5539.05$ \\
Particle size (nm) & $12.18 \mathrm{~nm}$ & \\
Zeta potential (mV) & $-17,6$ & \\
In vitro dissolution (\%) & 106.71 (15 minutes) & \\
\hline
\end{tabular}

\section{CONCLUSION}

Based on the optimization results, the optimum formula was at a concentration ratio of $61.4922 \%$ of Tween 80 and $18.5078 \%$ of PEG 400 . It went with the characterization of emulsification time of 15.25 seconds, percent transmittance of $94.20 \%$, drug loading of $50100.2 \mathrm{ppm}$, the particle size of $12.18 \mathrm{~nm}$, the zeta potential of $-17.6 \mathrm{mV}$, and the in vitro dissolution rate of $106.71 \%$ within 15 minutes.

\section{ACKNOWLEDGMENT}

The author would like to thank those who helped and were involved in this research.

\section{CONFLICT OF INTEREST}

The authors certify that they have no affiliations with or involvement in any organization or entity with any financial or non-financial interest in the subject matter or materials discussed in this manuscript.

\section{REFERENCES}

1. Sweetman, S. C. (2009). Martindale: The Complete Drug Reference. Thirty- sixth Edition.. London; Chicago: Pharmaceutical Press.

2. Wahyuningsih, I., Sugiyanto, S., Yuswanto, Ag., Martien, R. (2017). The Dissolution and Diffusion of Furosemide on Self-Nanoemulsifying Drug Delivery System (SNEDDS). Indonesian Journal of Pharmacy, 28(2), p. 112. http://dx.doi.org/10.14499/indonesia njpharm28iss2pp112

3. Wahyuningsih, I., Sugiyanto, S., Yuswanto Y., Martin R. (2015). Uji Kelarutan untuk Seleksi Fase Minyak, Surfaktan, dan Kosurfaktan dalam Preparasi Selfnanoemulsifying Drug Delivery System (SNEDDS) Furosemid. Prosiding Seminar Nasional Peluang Herbal sebagai Alternative Medicine.

4. Sakloetsakun, D., Dunnhaupt, S., Barthelmes, J., Perera, G., BernkopSchnurch, A., (2013). Combining Two Technologies: Multifunctional Polymers and Self-Nanoemulsifying Drug Delivery System (SNEDDS) for Oral Insulin Administration. 
International Journal of Biological Macromolecules, 61, pp. 363-372. http://dx.doi.org/10.1016/j.ijbiomac.2 013.08 .002

5. Mohammed, A.A., Selman, H.M., Abukhanafer, G. (2018). Liquid Surfactant Membrane for Lead Separation from Aqueous Solution: Studies on Emulsion Stability and Extraction Efficiency. Journal of Environmental Chemical Engineering. 6(6), pp. 6923-6930.

6. Rahayu, N. Y., Budiharjo, A., Pangastuti, A., Artanti, A.N., Prihapsara, F., Harini, M. (2019). Optimation Formula of SNEDDS Dosage from Ethanol Extract of Turmeric (Curcuma domestica) With Waste Oil of Eel (Anguilla spp.) as A Carrier. In IOP Conference Series: Materials Science and Engineering, 578. http://dx.doi.org/10.1088/1757899X/578/1/012049

7. Patel, D.M., Patel, N.M., Pandya, N.N., Jogani, P.D. (2007). Gastroretentive Drug Delivery System of Carbamazepine: Formulation Optimization Using Simplex Lattice Design: A Technical Note. PharmSciTech, 8 (1), p. 11. http://dx.doi.org/10.1208/pto801011

8. Winarti, L., Suwaldi, S., Martien, R., Hakim, L. (2018). Formulation of Insulin Self Nanoemulsifying Drug Delivery System and Its In Vitro-In Vivo Study. Indonesian Journal of Pharmacy, 29 (3), pp. 157 - 166. http://dx.doi.org/10.14499/indonesia njpharm2giss3pp157

9. Astuti, I. Y., Marchaban, M., Martien, R., Nugroho, A.E. (2018). Physical
Characterization and Dissolution Study of Pentagamavunon-o Loaded Self Nano-Emulsifying Drug Delivery System. Indonesian Journal of Pharmacy, 29 (2), 60 - 65 . http://dx.doi.org/10.14499/indonesia njpharm2giss2pp6o

10. Sahumena, M.H., Ikawati, Z. (2014). Pengembangan Nanopartikel Ketoprofen dengan Teknik SNEDDS dan Uji Aktifitas Antiinflamasi. [Tesis]. Yogyakarta: Program Pasca Sarjana, Universitas Gadjah Mada, Yogyakarta.

11. Patel, J., Patel, A., Raval, M., Sheth, N. (2011). Formulation and development of a Self-nanoemulsifying Drug Delivery System of Irbesartan. Journal of Advanced Pharmaceutical Technology and Research. 2(1), pp. 916. http://dx.doi.org/10.4103/22314040.79799

12. Ahmad, J., Kohli, k., Mir, S.R., Amin, S. (2011). Formulation of SelfNanoemulsifying Drug Delivery System for Telmisartan with Improved Dissolution and Oral Bioavailability. Journal of Dispersion Science and Technology 32 (7), pp. 958968.https://doi.org/10.1080/01932691 .2010 .488511

13. Syukri, Y., Fitriani, H., Pandapotan, H., Nugroho, B.H. (2019). Formulation, Characterization and Stability of Ibuprofen-Loaded SelfNano Emulsifying Drug Delivery System (SNEDDS). Indonesian Journal of Pharmacy. 30(2), pp. 105-113. http://dx.doi.org/10.14499/indonesia njpharm3oiss2pp105-113 
14. Parmar, N., Singla, N., Amin, S., Kohli, K. (2011). Study of Cosurfactant Effect on Nanoemulsifying Area and Development of Lercanidipine Loaded (SNEDDS) Self nanoemulsifying Drug Delivery System. Colloids and surface $B$ : biointerfaces. Elsevier. 86(2), pp. 327338.

https://doi.org/10.1016/j.colsurfb.201 1.04.016

15. Basalious, E. B., Shawky, N., BadrEldin, S.M., (2010). SNEDDS containing bioenhancers for improvement of dissolution and oral absorption of lacidipine. I: development and optimization. International Journal of Pharmaceutics. 391, pp. 203-211. https://doi.org/10.1016/j.ijpharm.201 $\underline{0.03 .008}$ 